V.N. Najm
Production \&
Metallurgy
Engineering
Department, University
of Technology,
Baghdad, Iraq
vean.nihad@gmail.com

Received on: 07/06/2017

Accepted on: 23/11/2017

\title{
Experimental Investigation of Wire EDM Process Parameters on Heat Affected Zone
}

\begin{abstract}
It is vital to study the impact of heat since it has an unwanted phenomenon on the operating life of parts produced, which is in turn effect the cost of production. when dimension accuracy is the primary function Wire cut machining comprehensively used specially when machining hard metal by using precisely controlled sparks that occur between a very thin wire and a workpiece in the presence of a dielectric fluid. The aim of this research is to study the effects of some Wire Electrical Discharge Machining (WEDM) variables on heat affected zone, white layer and Surface Roughness (SR) of high speed steel using ANOVA method to analyze the behavior of control parameters such as pulse on time ( $\mu$ s), current and wire tension. Experimental investigations separates into two main parts in the first one the wire electrical discharge machining process was accomplished on smart EDM (Electra wire cut machine), and in the second part the roughness of the machined samples surface was tested and the samples were prepared to be measured. The results shows that the heat affected zone and the white layer are affected with the risen of the current and pulse on time values more than the risen in wire tension values, as well as the wire tension affects the surface roughness more than the current and pulse on time.
\end{abstract}

Keywords- WEDM, Heat affected zone (HAZ), White layer thickness (WLT), Surface Roughness (SR).

How to cite this article: V.N. Najm, "Experimental Investigation of Wire EDM Process Parameters on Heat Affected Zone," Engineering and Technology Journal, Vol. 36, Part A, No. 1, pp. 46-54, 2018.

\section{Introduction}

Wire electrical discharge machining is a nontraditional electro thermal machining process controlled by a number of process factor such as pulse duration, pulse interval, current, voltage ,Wire tension, wire feed and such other factors. For ideal machining performance the setting of input parameters plays a dynamic role on output parameter such as material removal rate, surface finish, hardness and wear resistance [1]. Where electrical energy is used to remove metal by generating electrical sparks that occurs between the electrodes the wire cut and the workpiece in the presence of dielectric [2]. A wire EDM is used to cut and machine conductive material which is difficult to machine by conventional machining process, during the machining process there is no mechanical contact between the electrode and the workpiece, they are separated by a gap, so there is no residual stresses in the work material, the material have been eroded through high extreme temperature generated in the closest spot between the electrode and the anode [3]. The wire cut machine is consist of a machine tool which includes a primary workTable (X-Y) on which change the performance of the produced part [6]. Figureure 2 shows the three created type of surfaces by wire EDM process. the workpiece is mounted and cramped, and an supplementary Table (U-V) and wire drive mechanism, the WEDM includes also power supply unit and dielectric supply unit, Figureure 1 shows wire cut EDM unit [4].

The outcome of WEDM on the machined material is very diverse to that of traditional machining processes, the wire cut operation contributes undesirable effect on the surface properties of the produced parts since the surface of the workpiece material is subjected to very high temperatures, causing the material to melt or vaporize [5]. In wire electrical discharge machining three type of layers generates, the first layer is a slim layer of spattered material that has been formed from molten material and a small amount of wire material. The second layer is the white layer which is also referred to as (the white zone) or (recast layer), this layer is formed during the melting and rapidly solidifying of the machined material that is not flushed away properly by the deionized water. The third layer is the heat affected zone layer which is tempered layer formed as the material has not been heated up so much as to reach melting temperature and the heat affected zone may 


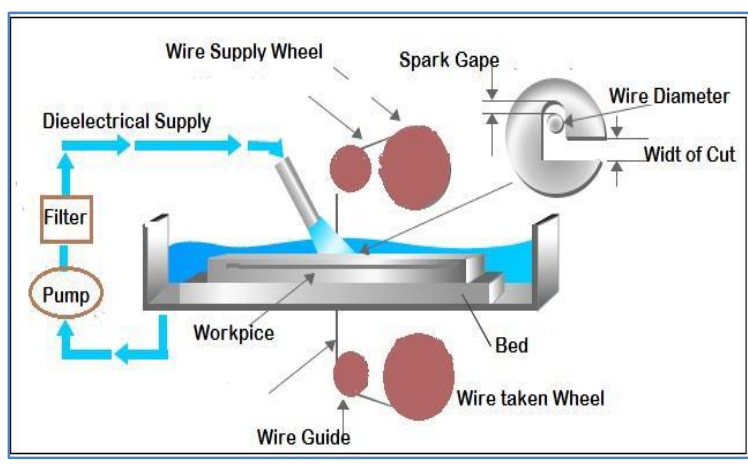

Figure 1: wire cut EDM unit [4]

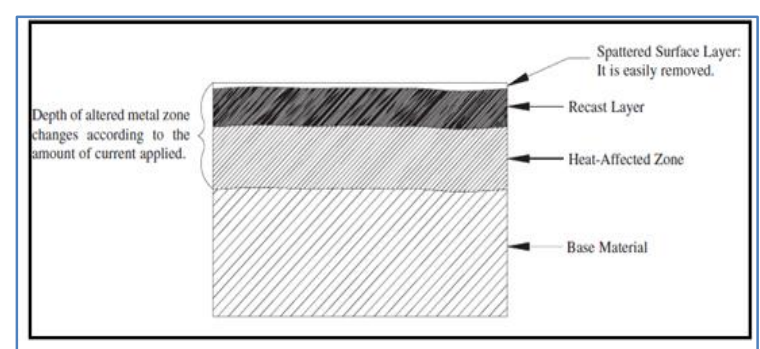

Figure 2: the three created type of surface by wire EDM process [6]

\section{2- Literature review}

In order to produce components that will have a satisfactory production life, a lot of researches adopted to study the WEDM process influence on produced material such as:-

They investigated the evaluation of the depth of heat-affected zone in sub-surface layers of the parts of tool steel produced by wire electrical discharge machining with brass electrode. They have been observed from these experiments the (HAZ) depth values vary in particular lines, as shown in Figureure 3 [7].

In this research the effect of wire electrical discharge machining on the fracture toughness of aluminum 7075-T6511was studeid. It was found that the fracture toughness was to be considerably reliant on the influence of the wire cut process on the material. It was concluded that WEDM is not a possible alternative to generate a precrack in a compact tension specimen to achieve fracture toughness testing of aluminum 7075-T6511 [8]. In this paper the effect of wire EDM process on the surface integrity was studied using a coated wire electrode, the adaptive neuro-fuzzy inference system (ANFIS) was used to predict the White layer thickness (WLT) in WEDM [9]. It was concluded that the smallest value of WLT is reached at the minimum levels of peak current and pulse duration with high level of pulse interval. In this research experiments performed on the EN31die steel in order to study the effect of various machining parameter such as pulse on time, current, discharge gap voltage on the heat affected zone of the machined surface using different electrode material, it was concluded that the copper electrode gives higher material removal rate than other electrodes, while the brass electrode presents greater surface finish, and the brass electrode gives much deeper heat affected zone [10]. In This research the influence of the machining parameters were studied in order to improve the machining performance of wire cut process. Adaptive neuro-fuzzy inference system (ANFIS) was used to determine the effect of different factors on WEDM performance. In addition, ANFIS was used to predict the cutting speed, surface roughness and heat affected zone in WEDM. The predicted cutting speed, surface roughness, and heat-affected zone were compared with measured data, and the average prediction error for cutting speed, surface roughness, and heat affected zone [11].

\section{3- Experimental Procedure}

Surface quality is very essential parameter for the produced component on which its affect the operating life of the produced part. It is dynamic to mention the heat impact is unwanted phenomenon for the operating life of parts produced by this advanced technology, and its characteristic is depth of heat affected zone which is decline the quality and endurance of the produced machine parts . Experimental investigations separates into two main parts in the first one the wire electrical discharge machining process was accomplished on smart EDM (electra wire cut machine), as shown in Figureure 4, and Figureure 5 shows the cutting wire (coated brass wire), where the machining parameters have been controlled by the WEDM machine controller in order to investigate the effect of machining parameters on heat affected zone, white layer and surface roughness. Specification of the machine has been written in Table 1 . The electra wire cut machine contain a machine tool, a power supply unit and dielectric supply unit, the power supply unit includes motor driver unit for $\mathrm{X}, \mathrm{Y}, \mathrm{U}, \mathrm{V}$ axes, electric pulse generator and the controller. The movement of the wire is fed to the part programming system-using keyboard; the machine specification is shown in Table 1. 


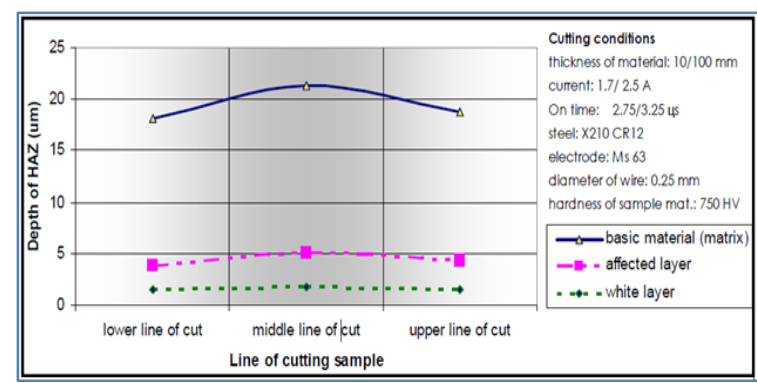

Figure 3: measured values of $\mathrm{HAZ}$ depth in the three lines [7]

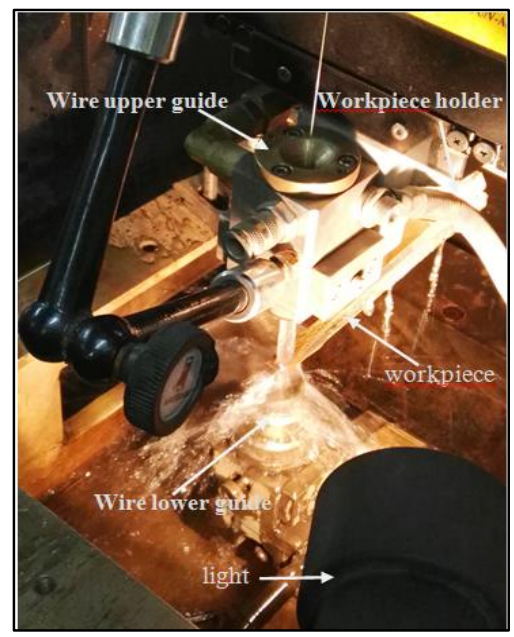

Figure 4: Electro wire cut machine

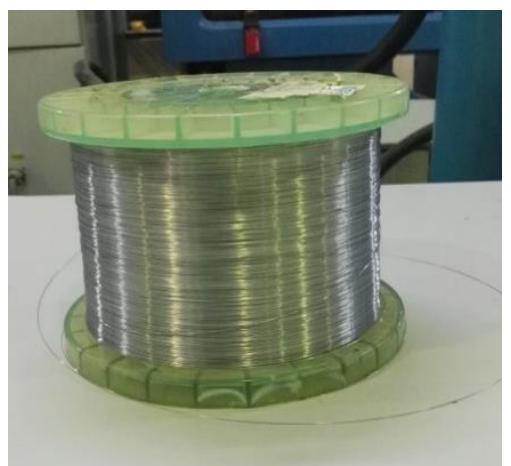

Figure 5: Coated brass wire

Table 1: WEDM machine specification

\begin{tabular}{ll}
\hline $\begin{array}{l}\text { Maximum work pieces } \\
\text { dimensions }\end{array}$ & $\begin{array}{l}630 \times 440 \times 300 \\
\mathrm{~mm} .\end{array}$ \\
\hline Maximum work piece weight & $500 \mathrm{~kg}$ \\
Machine weight. & $2000 \mathrm{~kg}$ \\
Maximum Table feed rate & $180 \mathrm{~mm} / \mathrm{min}$ \\
Wire diameter & $0.25 \mathrm{~mm}$. \\
Wire tension & $1600 \mathrm{~g}$ \\
Tolerance & $0.001 \mathrm{~mm}$ \\
Guide of wire & Steel \\
Dielectric fluid & Deionized water \\
Supply voltage & $400 \mathrm{~V}$. \\
Power & DC power \\
\hline
\end{tabular}

Experimental samples that is used in this study is made from high speed steel of $(10 \times 10 \times 120) \mathrm{mm}$, Figureure 6: shows the workpiece before machining and Figureure 7: shows the workpiece after machining .For new industrial production, machining process is one of the most significant modeling and forming processes. the high speed steel is not just used for cutting tools, it is also employed for various forming tools in the recent time, the chemical properties is shown in Table 2: this test was carried out in (Midland refineries company/ general company MRC baghdad). A coated brass wire with $0.25 \mathrm{~mm}$ diameter is used as a cutting tool in order to machine a work material of high speed steel Figureure 5: show the coated brass wire. Experiments were made to determine and study the depth of HAZ with variation in input parameters the Table 3 shows the variation of input parameters that used in this experiment in order to control the machine parameter to reach the desired surface quality. Pure (distilled) water was used as a dielectric fluid. The machining parameters and its levels used in this experimental work is shown in Table 3.

After the metal was machined by wire electrical discharge machining process the second part of the experiments started, at first the roughness of the machined samples surface was tested by using a porTable surface roughness measuring device (pocket surf) made by Mahr company, Figureure 8: Shows surface roughness device. These tests has been carried out in (Laboratories of Department of Production Engineering and Metallurgy of the University of Technology). Then the samples were prepared to be measured. In this stage the samples were grinded with silicon carbide paper of grit sizes $(120,320,500,1000,1200)$, then the samples were polished with a semiliquid mixture of alumina $\left(\mathrm{Al}_{2} \mathrm{O}_{3}\right)$, after the polishing process etching process was performed by using chemical acid to appear the interfaces of the workpiece under the optical microscope, in order to measure the heat affected zone and the white layer thicknesses, the optical microscope shown in Figureure 9. These tests has been carried out in (Laboratories of Department of production engineering and Metallurgy of the University of Technology).

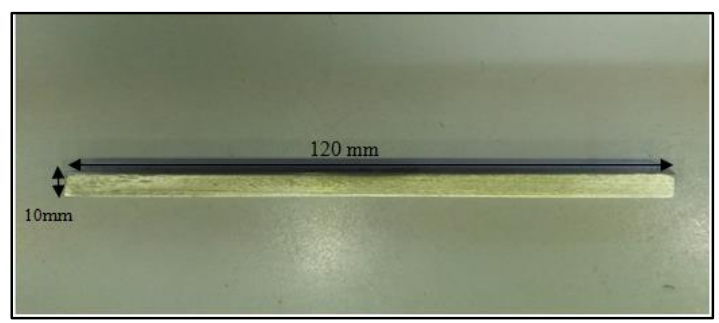

Figure 6: shows the workpiece before machining 


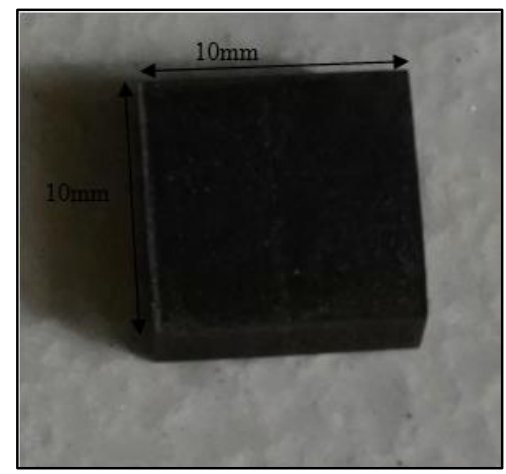

Figure 7: shows the workpiece after machining

Table 2: the chemical properties of the workpiece

\begin{tabular}{lrrrrrrrr}
\hline Material & $\mathbf{C}$ & $\mathbf{S i}$ & $\mathbf{M n}$ & $\mathbf{C r}$ & $\mathbf{M o}$ & $\mathbf{T i}$ & $\mathbf{V}$ & $\mathbf{F e}$ \\
\hline Chemical analysis\% & 1.1 & 1.28 & 0.26 & 1.08 & 0.08 & 0.007 & 0.01 & balance \\
\hline
\end{tabular}

Table 3: Machining parameters used in experimental work

\begin{tabular}{lccc}
\hline Parameters & Level (1) & Level (2) & Level (3) \\
\hline Pulse on time $(\mu \mathrm{s})$ & 110 & 115 & 120 \\
\hline Pulse current $(\mathrm{A})$ & 10 & 11 & 12 \\
\hline Wire tension $(\mathrm{kgf})$ & 5 & 7 & 9 \\
\hline
\end{tabular}

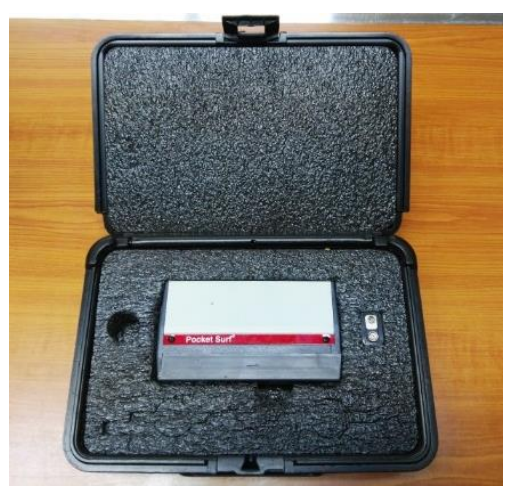

Figure 8: Shows surface roughness device (Pocket Surf)

\section{5- ANOVA Analysis}

Analysis of variance (ANOVA) able to evaluate the influence of a machining parameter on the characteristic property which significantly affects the quality characteristic [12] to discover out the importance of prime factors and interaction factors the analysis of variance (ANOVA) method has been used. ANOVA is implemented to see statistically important process parameters and percent influence of these parameters on the machined workpiece properties. Larger F-value specifies that the diversity of the process parameter produce a large

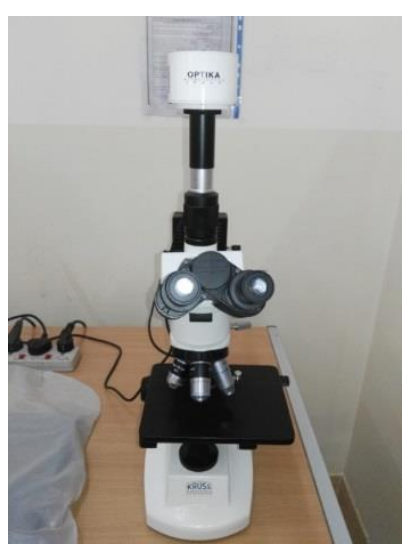

Figure 9: Optical microscope modification on the performance characteristics [13]. MINITAB 17 was used to make the statistical analysis of the data in addition to the drawing of curves. This analysis use to discover out the influence of process parameter in controlling the output factors of the wire EDM process. The "R-sq" value is the coefficient of determination in Table 5:, Table 7:, Table 9: shows how much variation in the response is explained by the model, the efficiency for all situations toward affecting the related output response characteristics within the limited range. 
Table4: the analysis of variance for HAZ:

\begin{tabular}{llllll}
\hline Source of variance & Degree of freedom & Sum of squares (ss) & Mean squares (MS) & F ratio & p-value \\
\hline Pulse on time & 2 & 1638 & 818.8 & 1.46 & 0.304 \\
Current & 2 & 2841 & 1420.4 & 3.94 & 0.081 \\
Wire tension & 2 & 523.6 & 261.8 & 0.35 & 0.718 \\
Total & 8 & 5003 & & & \\
\hline
\end{tabular}

Table 5: The Model Summery of heat affected zone.

\begin{tabular}{lll}
\hline Source & S & R-sq \\
\hline Pulse on time & 23.6832 & $32.73 \%$ \\
Current & 18.9829 & $56.78 \%$ \\
Wire tension & 27.3230 & $10.47 \%$ \\
\hline
\end{tabular}

Table 6: the analysis of variance for WLT:

\begin{tabular}{llllll}
\hline $\begin{array}{l}\text { Source of } \\
\text { variance }\end{array}$ & $\begin{array}{l}\text { Degree of } \\
\text { freedom }\end{array}$ & $\begin{array}{l}\text { Sum of } \\
\text { squares (ss) }\end{array}$ & $\begin{array}{l}\text { Mean squares } \\
(\mathrm{MS})\end{array}$ & F ratio & p-value (\%) \\
\hline Pulse on time & 2 & 15.70 & 7.851 & 4.0 & 0.079 \\
Current & 2 & 8.548 & 4.274 & 1.35 & 0.327 \\
Wire tension & 2 & 2.288 & 1.144 & 0.27 & 0.771 \\
Total & 8 & 27.49 & & & \\
\hline
\end{tabular}

Table 7: The Model Summery of white layer thickness.

\begin{tabular}{lll}
\hline Source & $\mathrm{S}$ & $\mathrm{R}$-sq \\
\hline Pulse on time & 1.40158 & $57.12 \%$ \\
Current & 1.77668 & $31.10 \%$ \\
Wire tension & 2.04940 & $8.32 \%$ \\
\hline
\end{tabular}

Table 8: the analysis of variance for $\mathrm{Ra}$

\begin{tabular}{llllll}
\hline Source of variance & Degree of freedom & Sum of squares (ss) & Mean squares (MS) & F ratio & P-value (\%) \\
\hline Current & 2 & 0.1345 & 0.1345 & 0.06726 & 0.11 \\
Wire tension & 2 & 3.7519 & 1.87596 & 59.46 & 0.000 \\
Total & 8 & 3.94120 & & & \\
\hline
\end{tabular}

Table 9: The Model Summery of surface roughness.

\begin{tabular}{lll}
\hline Source & $\mathrm{S}$ & $\mathrm{R}-\mathrm{sq}$ \\
\hline Pulse on time & 0.801475 & $2.21 \%$ \\
Current & 0.796522 & $3.41 \%$ \\
Wire tension & 0.177616 & $95.20 \%$ \\
\hline
\end{tabular}

\section{6- Results and Discussion}

The results of experimental work for samples machined by WEDM to measure the depth of heat affected zone (HAZ) and the thickness of the white layer with the aim of founding the best machining parameters for getting extended operating life for the product made by this advanced machining process. The final supply of the experiments levels and results of heat affected zone, white layer thickness and surface roughness are shown in Table 10.

Table 10: shows the Experimental results.

\begin{tabular}{lllllll}
\hline NO & Pulse on time $(\mu \mathrm{s})$ & Current $(\mathrm{A})$ & Wire tension $(\mathrm{kgf})$ & HAZ $(\mu \mathrm{m})$ & WLT $(\mu \mathrm{m})$ & $\mathrm{SR}(\mu \mathrm{m})$ \\
\hline $\mathbf{1}$ & 110 & 11 & 7 & 33.53474 & 10.86705 & 2.62 \\
$\mathbf{2}$ & 115 & 11 & 7 & 54.618178 & 12.367 & 2.83 \\
$\mathbf{3}$ & 120 & 11 & 7 & 90.369538 & 16.3316 & 2.99 \\
$\mathbf{4}$ & 115 & 10 & 7 & 34.0883788 & 11.811316 & 2.57 \\
$\mathbf{5}$ & 115 & 11 & 7 & 54.618178 & 12.367 & 2.83 \\
$\mathbf{6}$ & 115 & 12 & 7 & 105.78918 & 15.64927 & 3.06 \\
$\mathbf{7}$ & 115 & 11 & 5 & 39.63424 & 11.807928 & 4.48 \\
$\mathbf{8}$ & 115 & 11 & 7 & 54.61817 & 12.367006 & 2.83 \\
$\mathbf{9}$ & 115 & 11 & 9 & 70.0884 & 13.89907 & 1.80 \\
\hline
\end{tabular}


The growth in the depth of heat affected zone and thickness of white layer by the rise in pulse on-time with values $(110,115$ and $120 \mu \mathrm{s})$ as it can be obviously realized from the experimental results appear in Figureures 10,11, 12, 13, 14 and 15. The explanation for this phenomenon is that the intensity of the spark increased, and the flushing efficiency has a harsh influence, which is necessary to flush away the eroded particles of the workpiece and wire material [14]. With an growth in pulse duration, flushing efficiency falls and spark intensity risen which in turn leads to the rise of the white layer thickness and the depth of HAZ as well as the surface roughness increases too. The analysis of variance reveal that the effect of pulse on time has effect more than the wire tension on the heat affected zone but not more than the current also unveil that the Pulse on time has the most significant effect on the WLT more than the current and wire tension, but on the surface roughness has slight effect.
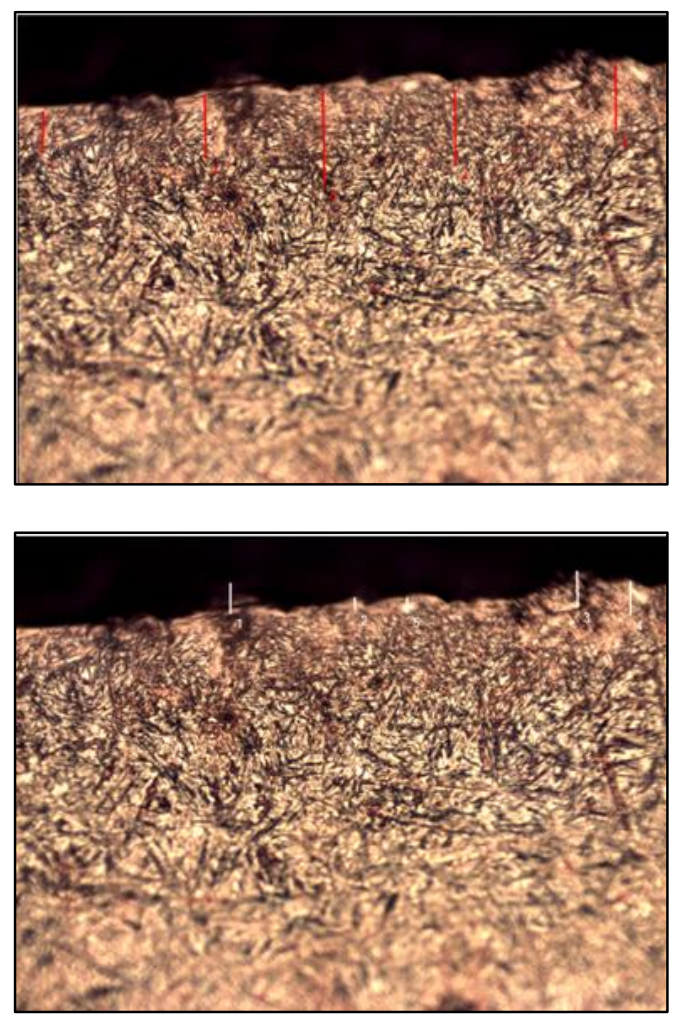

Figure 10 \& 11: Cross section micrograph HAZ \& WLT at TON=110
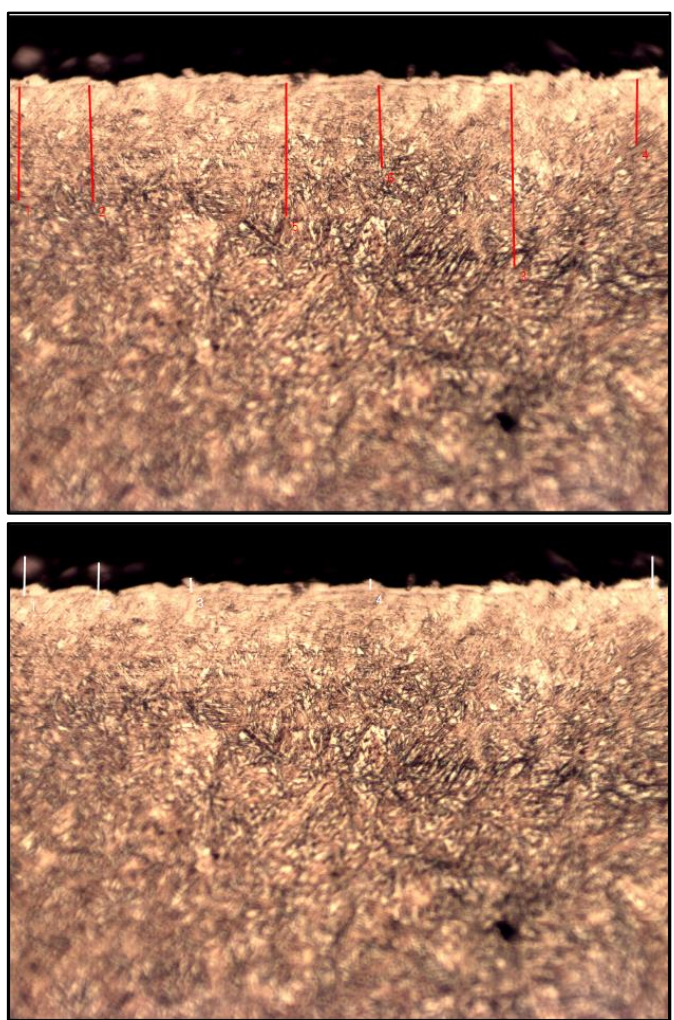

Figureure $12 \&$ 13: Cross section micrograph HAZ \& WLT at TON=115
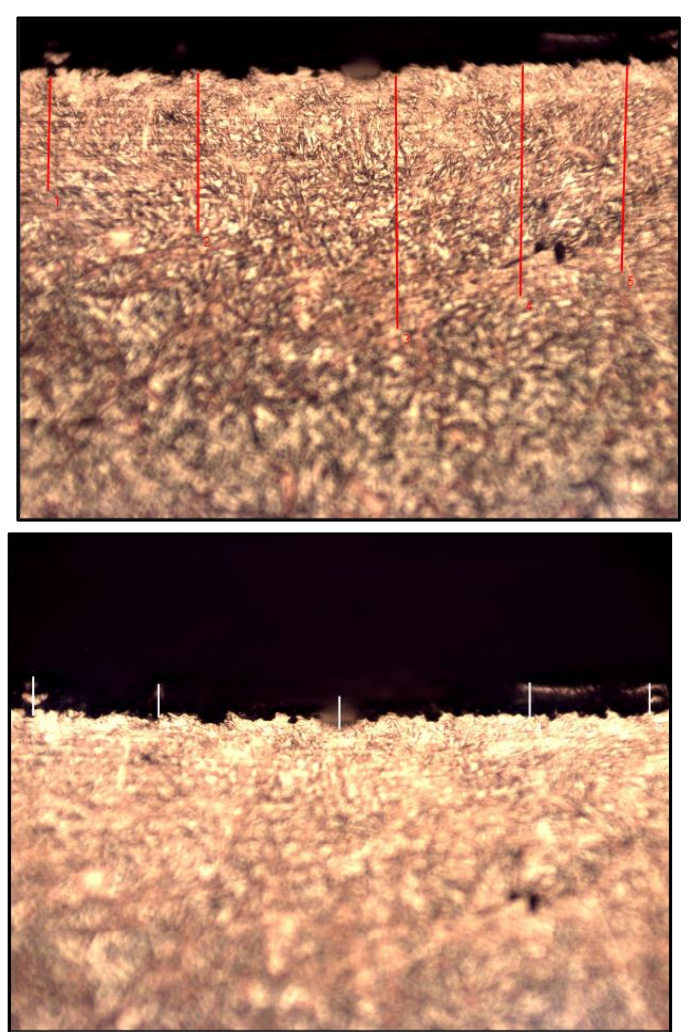

Figure 14 \& 15: Cross section micrograph HAZ \& WLT at TON=120

The depth of HAZ and the thickness of white layer is increased with increase in pulse current as it can be noticeably realized from the experimental results 
appear in Figureures 16,17 ,18, 19, 20 and 21. The logical explanation for this is when the pulse current is increased, the intensity of the spark risen and discharge power are growth, subsequently causing a additional amount of heat generated on the surface of the work piece, which resulted in upturn the depth of HAZ and the thickness of white layer, and also surface roughness increases too, as the pulse current increases, discharge strikes the surface of the sample more intensely, and causes more molten material to be ejected from the surface causing more crater to be found on the surface, so the surface roughness of the machined surface increases [15]. The ANOVA analysis expose that current has the main influence on the heat affected zone more than the TON and WT, and also the white layer thickness increases too by increase in current values as well as the surface roughness increases too.
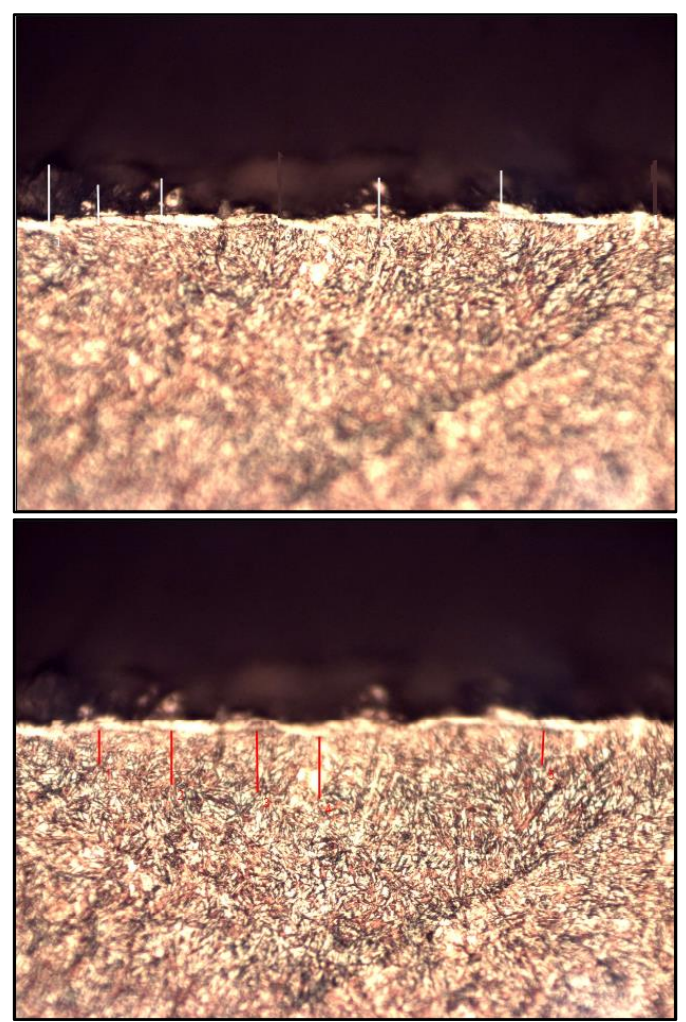

Figure 16 \& 17: Cross section micrograph HAZ \& WLT at Ip=10.

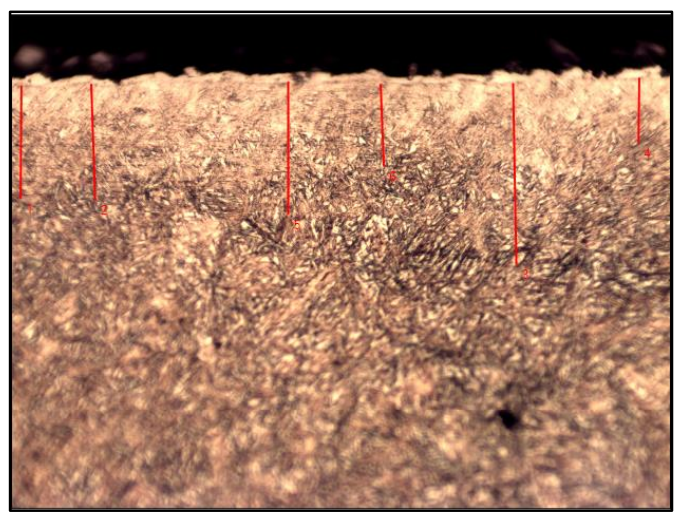

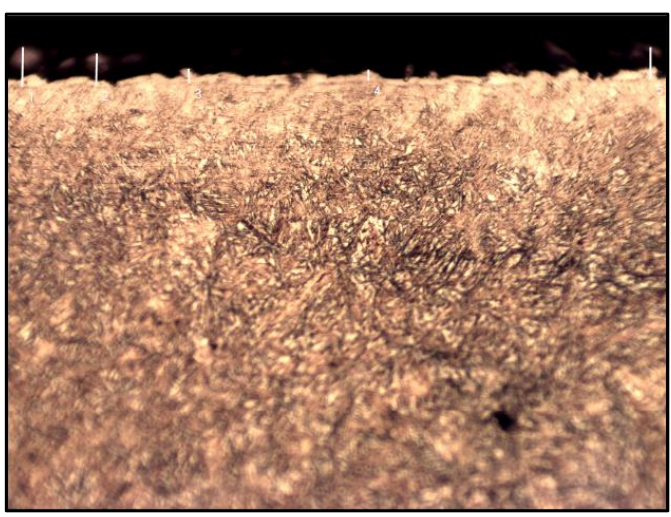

Figure 18 \& 19: Cross section micrograph HAZ \& WLT at Ip=11.
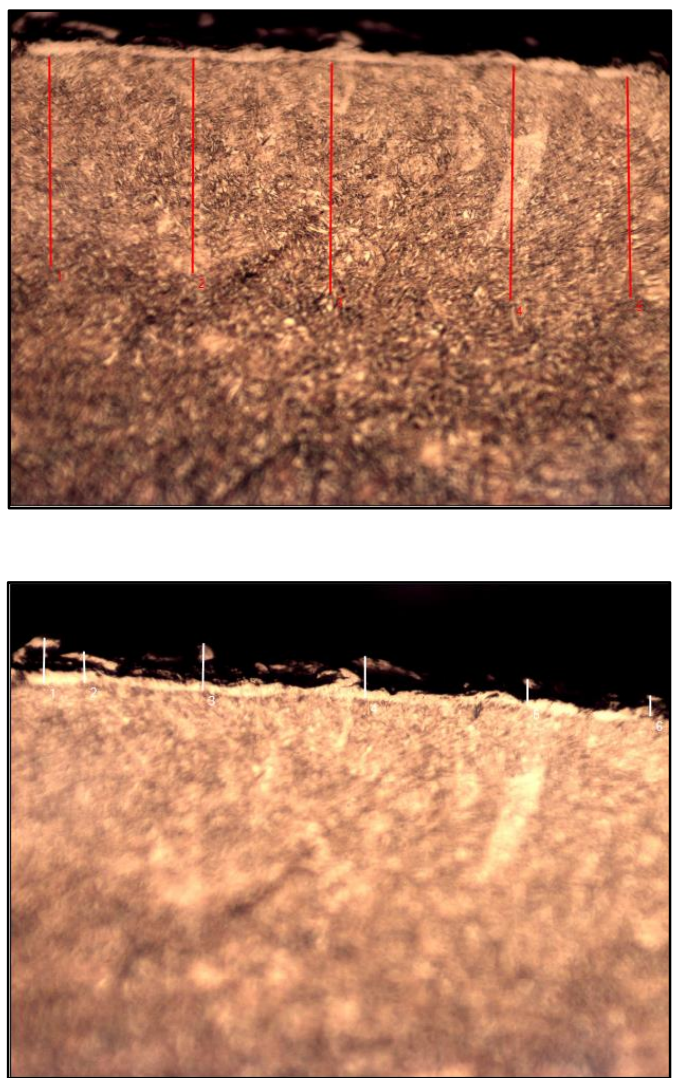

Figure 20\& 21: Cross section micrograph HAZ \& WLT at $I p=12$

The wire tension has slight effect on the heat affected zone and white layer as it can be clearly understood from the experimental results shown in Figures 22, 23, 24, 25, 26 and 27. but it has great effect on the surface roughness. The analysis of variance disclose that the wire tension has effect more than the current and pulse on time on the surface roughness but on less effect on the heat affected zone and the white layer thickness than the other two parameters. 

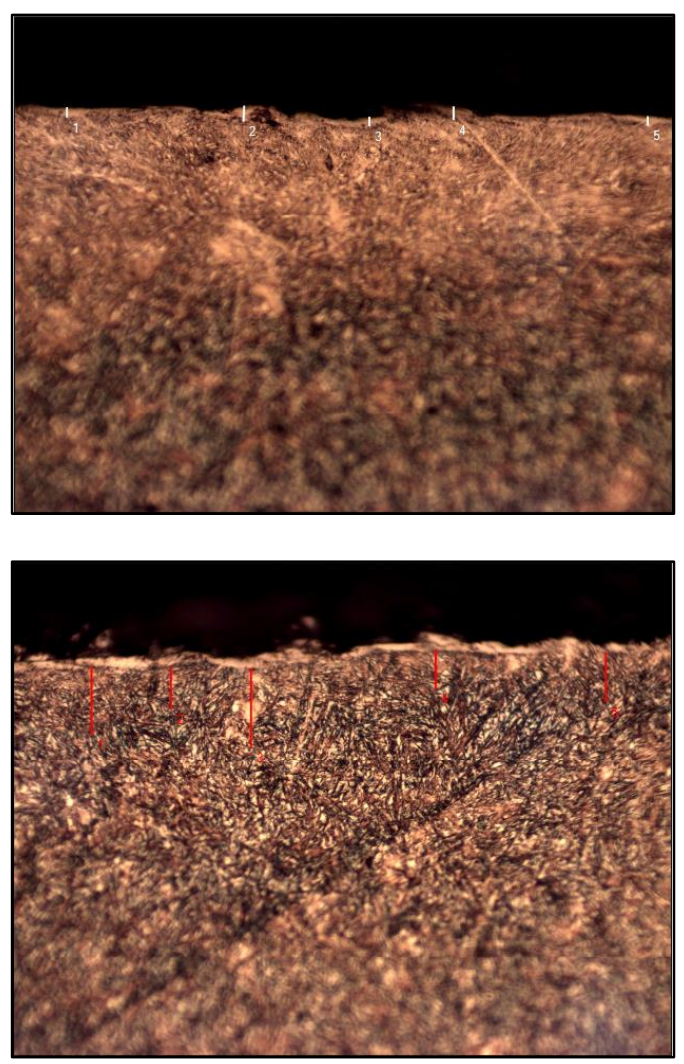

Figure 22 \& 23: Cross section micrograph WLT \& HAZ at WT $=5$

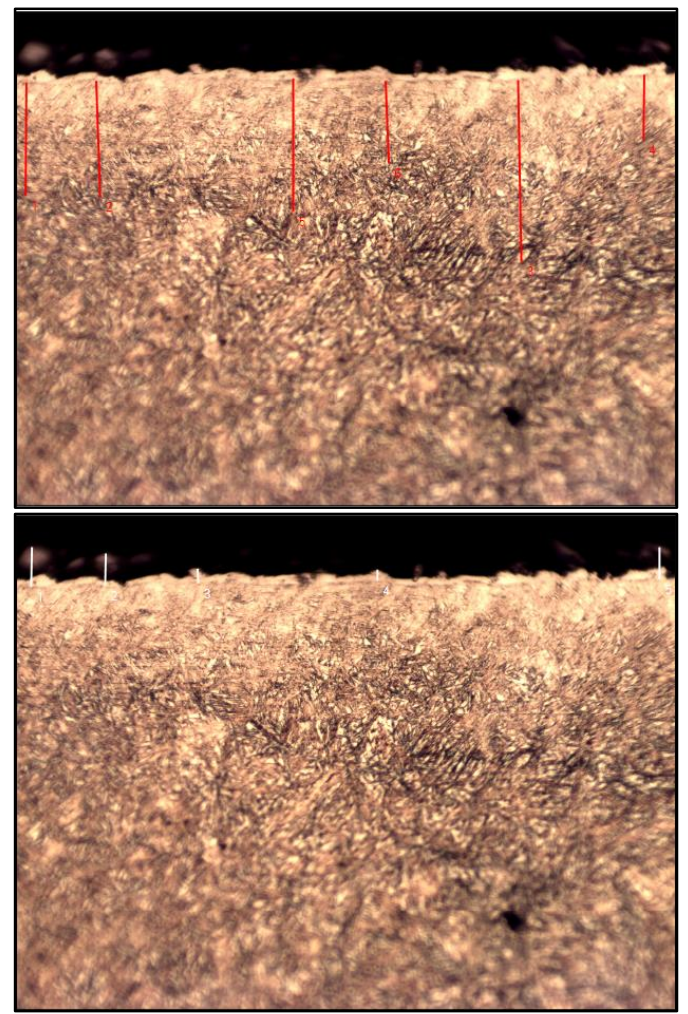

Figure 24 \& 25: Cross section micrograph HAZ \& WLT at Ip=11.

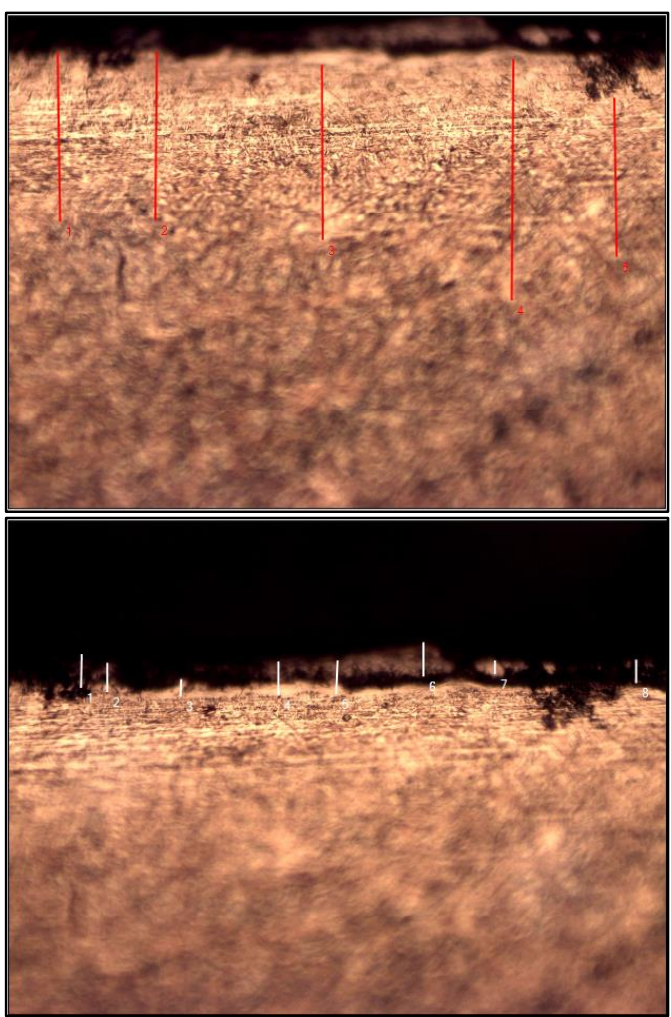

Figure 26 \& 27: Cross section micrograph WLT \& HAZ at WT=9

Figure (28, 29 and 30) shows the plot of the means of the influence of the machining inputs on the heat affected zone, white layer thickness and surface roughness separately.

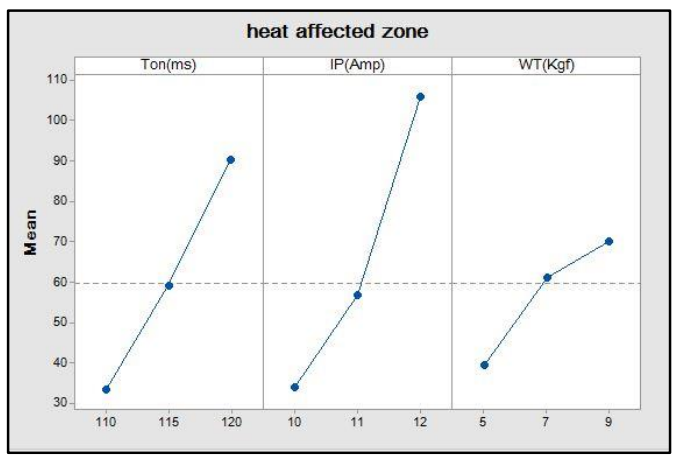

Figure 28: shows the variation of HAZ with the three process parameters.

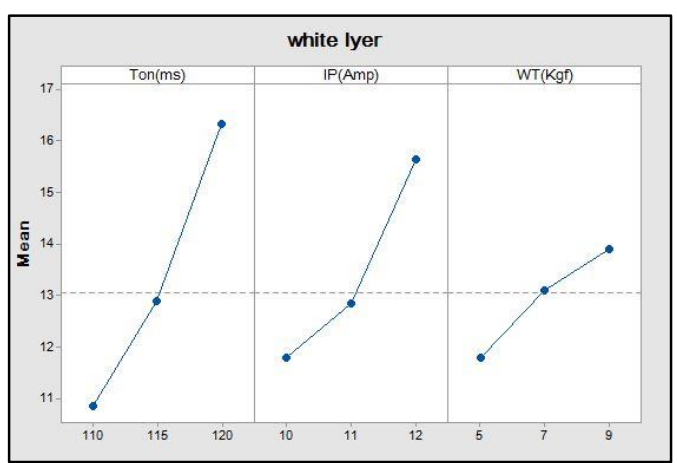


Figurer 29: shows the variation of WLT with the three process parameters.

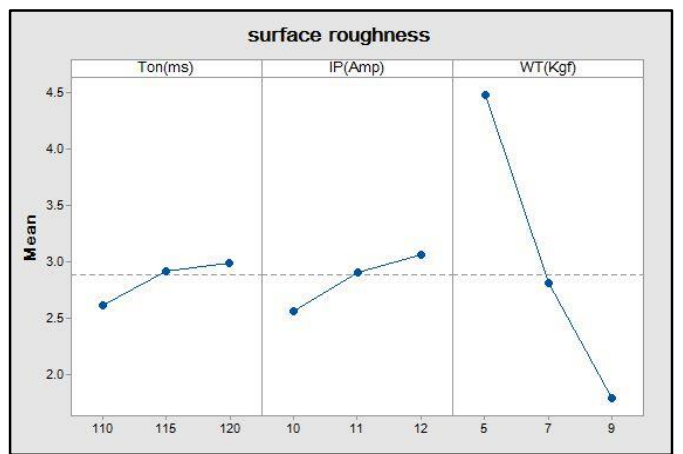

Figurer 30: shows the variation of SR with the three process parameters

\section{8- Conclusions}

In this study, the experimental results reveal the following:

1-The best input parameters that are gives less heat affected zone and white layer thickness are at pulse on time $(110 \mu \mathrm{s})$, current (11A) and wire tension (7 kgf).

2 -The best surface roughness is obtained at wire tension (9 kgf). Analysis of variance analyzed that the heat affected zone is more affected with current parameter than pulse on time and wire tension.

3 -The ANOVA method assured that the current is the most important parameter that influence the heat affected zone by $56.78 \%$, and found that pulse on time $\left(\mathrm{T}_{\mathrm{ON}}\right)$ is the most significant cutting parameters affect white layer by $57.12 \%$, and the wire tension is the most important cutting parameters influencing surface roughness by $95.20 \%$.

\section{References}

[1] R. Bhatia, S. Kumar, "Experimental Analysis of Surface Roughness for Heat Treated H-11 Die Steel by WEDM," International Journal of Research in Mechanical Engineering \& Technology, Vol.3, Issue 2, pp.109-111, 2013.

[2] V. Kumar, A. K. Yadav, I. Singh, "A review on current research trends in wire-electrical discharge machining (WEDM)," International Journal of science technology and management, Vol.5, Issue 1, pp.103112, 2016.

[3] R.N. Yadav, A. Pandey, S. Kumar, “'Modelling and Optimization of Wire-EDM Process using Integrated Approach of ANN-GA," International Journal of Research and Development in Applied Science and Engineering, Vol.10, Issue 1, 2016.

[4] V.S. Bhandari, P. Patidar, "Optimization of wire cut EDM process parameters for copper and aluminum part: a review," International Journal of Engineering
Applied Sciences and Technology, Vol.1, Issue 8,pp 260-262, 2016.

[5] WWW.uddeholm.com.

[6] C. Sommer, S. Sommer, "Complete EDM hand book11,"pp.148-153, 2010.

[7] L. STRAKA, I. ČORNÝ, J. BORŽÍKOVÁ, V. SIMKULET, "Course of heat affected zone depth in the cross sample after WEDM cutting," Annals of the faculty of engineering hunedoara, Journal of engineering, PP.232-236, 2008.

[8] D.M. Madyira, "Effect of Wire EDM on microstructure and fracture toughness of 7075-T6511 aluminum alloy," Proceedings of the World Congress on Engineering, Vol.2, 2015.

[9] I. Maher, A.A.D. Sarhan, H. Marashi, M.M. Barzani and M. Hamdi, " White layer thickness prediction in wire-EDM using CuZn-coated wire electrode - ANFIS Modeling", The International Journal of Surface Engineering and Coatings, Vol.94, Issue 4, pp.204-210, 2016.

[10] R. Choudhary, H. Kumar, R.K. Gray, "Analysis and evaluation of heat affected zones in electric discharge machining of EN-31 die steel," International journal of engineering and material sciences, Vol.17, pp.91-98, 2010.

[11] I. Maher, L.H. Ling, A.A.D. sarhan, M.H. abd shukor, "Improve wire EDM performance at different machining parameters-ANFIS modeling,"

[12] S.K. Shather, A.F. Ibrahim, D.A. Noori, "Experimental investigation to predict metal removal and surface roughness in wire cut process," Diyala Journal of Engineering Science, 2016.

[13] A.K. Hussein, "Optimization of Cyclic Oxidation Parameters in Steel-T21 for Aluminization Coating Using Taguchi-ANOVA analysis by MINITAB13," Engineer and Technology Journal, Vol.27, pp.2367 2384, 2009.

[14] L. STRAKA, I. ČOR Ný, J. Boržíkov, “Analysis of Heat-Affected Zone Depth of Sample Surface at Electrical Discharge Machining with Brass Wire Electrode," Strojarstvo : journal for the theory and application in mechanical engineering, Vol.51, pp.633640, 2009.

[15] H.A. EL-Hofy, "Advanced machining processes: Nontraditional and Hybrid machining processes," McGraw-Hill, chapter 5, pp.115-138, (2007).

\section{Author's biography}

Vian N. Najm, recived her B.Sc.degrees in 2006 in Production \& Metallurgy Engineering, and M.Sc. degree in 2014 in Production Engineering from the University of Technology, Iraq. 